\title{
Erratum to: Variations in preventive care utilisation in Europe
}

\author{
Florence Jusot $\cdot$ Zeynep Or $\cdot$ Nicolas Sirven
}

Published online: 20 December 2011

(C) Springer-Verlag 2011

\section{Erratum to: Eur J Ageing \\ DOI 10.1007/s10433-011-0201-9}

\section{TEXT AS IT NOW APPEARS}

$$
C_{i j}=\beta_{0}+W_{j} \lambda+\omega_{0 j}+X_{i j} \beta+e_{i j}
$$

The first stage of our analysis consisted of estimating the association between the probability of using each given service $\left(C_{i j}\right)$ and several individual explanatory variables ( $X_{i j}$ : age, sex, education income, health status). The slope coefficients $\beta$ of the individual explanatory variables were treated as fixed across countries. However, a random country intercept $\beta_{0 j}$ was introduced in the model in order to take into account the differences between country in the average level of use a given health service. Across countries, the country intercepts $\beta_{0 j}$ were assumed to be normally distributed with a mean $\beta_{0}$ and a variance $\sigma^{2}$. The estimate of the variance $\sigma^{2}$ provided then a measure of the differences in health care use across countries after controlling for compositional effect due to individual characteristics. If $\sigma^{2}$ was significantly different from zero, it indicated that the level of health services use significantly varies from one country to another.

The online version of the original article can be found under doi:10.1007/s10433-011-0201-9.

\section{F. Jusot}

Université Paris-Dauphine, LEDA-LEGOS, Place du Maréchal de Lattre de Tassigny, 75775 Paris Cedex 16, France

F. Jusot $\cdot$ Z. Or $(\bowtie) \cdot$ N. Sirven

IRDES, Institute for Research and Information on Health

Economics, 10 rue Vauvenargues, 75018 Paris, France

e-mail: or@irdes.fr
The second stage of the analysis aimed to establish the association between various health system features and the probability of service utilisation at the country level. In order to explain the variation in health care use across countries shown by the first stage of this analysis, health systems variables were introduced, in addition to individual characteristics. A random country intercept $\omega_{0 j}$ (normally distributed) was also introduced in the model in order to control for unobserved country-level factors influencing preventive care use independently of health system characteristics.

\section{THIS SHOULD READ AS:}

$C_{i j}=\beta_{0}+W_{j} \lambda+\omega_{0 j}+X_{i j} \beta+e_{i j}$

The first stage of our analysis consisted of estimating the association between the propensity of using each given service by individual $i$ in country $j\left(C_{i j}\right)$ and several individual explanatory variables $\left(X_{i j}\right.$ : age, sex, education income, health status). The slope coefficients $\beta$ of the individual explanatory variables were treated as fixed across countries. Furthermore, a random country intercept was introduced in the model in order to take into account the differences between country in the average level of use a given health service. Across countries, the country intercepts were assumed to be normally distributed with a mean $\left(\beta_{0}\right)$ and a variance. The estimate of the variance provided then a measure of the differences in health care use across countries after controlling for compositional effect due to individual characteristics. If the country variance was significantly different from zero, it indicated that the level of health services use significantly varies from one country to another.

The second stage of the analysis aimed to establish the association between various health system features and the 
probability of service utilisation at the country level. In order to explain the variation in health care use across countries shown by the first stage of this analysis, health systems variables $W_{j}$ were introduced, in addition to individual characteristics. In the model above with health system variables $\left(W_{j}\right)$, random country intercept $\omega_{0 j}$ (normally distributed) captures unobserved country-level factors influencing preventive care use independently of the impact of health system characteristics $(\lambda)$. 